\title{
USOS EDUCATIVOS DE LA NARRATIVA DIGITAL: UNA EXPERIENCIA DE M-LEARNING PARA LA EDUCACIÓN EMOCIONAL
}

Resumen: En este trabajo se presenta una experiencia de innovación educativa desarrollada en una Escuela de Arte dentro del ciclo de Lenguajes y Medios Audiovisuales. En esta experiencia se han aplicado diferentes técnicas: a) aprendizaje colaborativo soportado por ordenador para la enseñanza de habilidades sociales, b) narrativa digital para la enseñanza de competencias emocionales y c) utilización de dispositivos móviles para la enseñanza de competencias específicas de la asignatura en la creación de microformatos audiovisuales y competencias tecnológicas. En este artículo se describe el diseño de la experiencia educativa así como los resultados obtenidos en los tests y evaluaciones realizadas antes, durante y después del desarrollo de la misma.

Palabras clave: m-learning, narrativa digital, educación emocional, CSCL 


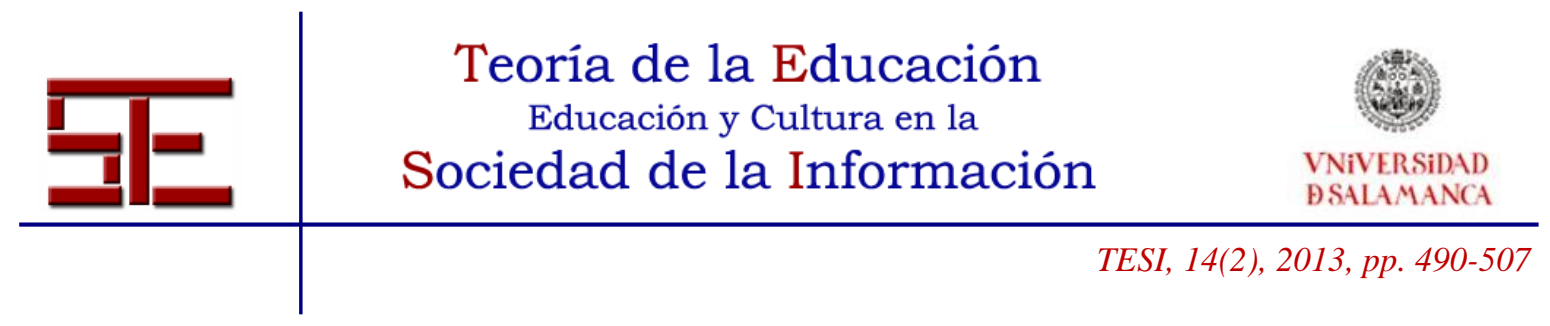

\section{EDUCATIONAL USES OF DIGITAL STORYTELLING: AN EXPERIENCE OF M-LEARNING FOR THE EMOTIONAL EDUCATION}

Abstract: This paper presents an educational innovative experience developed in an art school in the cycle of Language and Audiovisual Media. In this experience different techniques have been applied: a) computer-supported collaborative learning for teaching social skills, b) digital storytelling for teaching emotional skills c) use of mobile devices for teaching specific subject's skills in audiovisual creation and technological skills. This paper describes the design of this educational experience and their results.

Key words: m-learning, digital storytelling, emotional education, CSCL

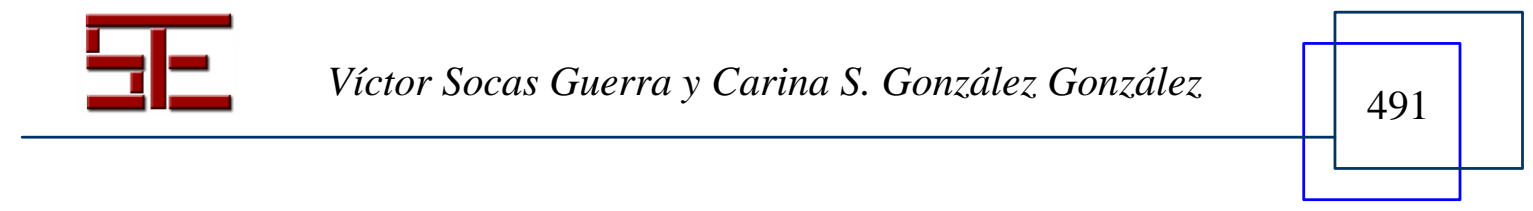




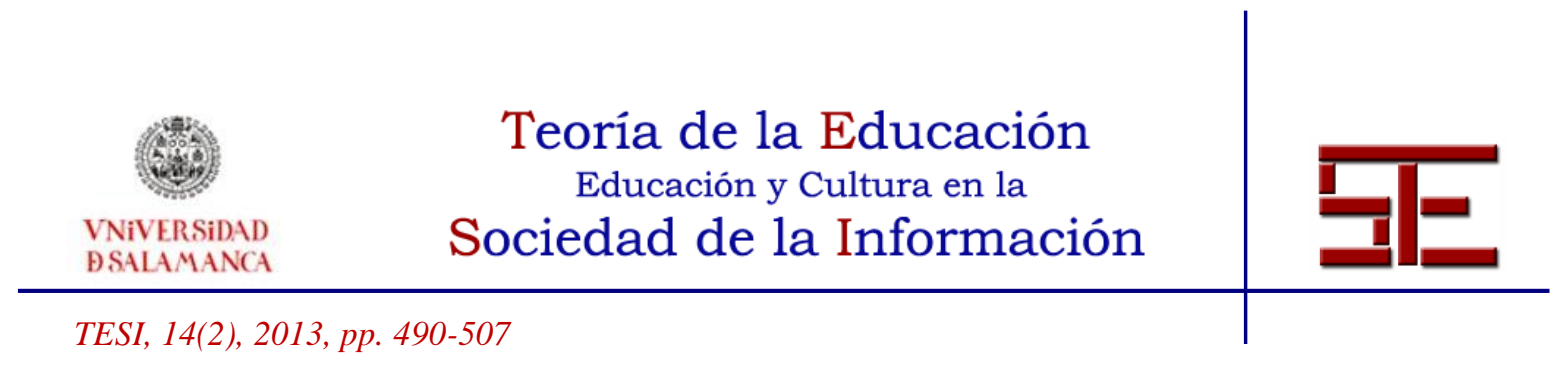

\section{USOS EDUCATIVOS DE LA NARRATIVA DIGITAL: UNA EXPERIENCIA DE M-LEARNING PARA LA EDUCACIÓN EMOCIONAL}

Fecha de recepción: 10/02/2013; fecha de aceptación: 01/06/2013; fecha de publicación: 30/07/2013

Víctor Socas Guerra

victorsocasguerra@gmail.com

Universidad de la Laguna

Carina S. González González

cjgonza@ull.es

Universidad de la Laguna

\section{INTRODUCCIÓN}

La inteligencia emocional se refiere a la capacidad de identificar, comprender y manejar las emociones en uno mismo y en los demás. Fernández Berrocal y Ramos (2002) definen a la inteligencia emocional como "la capacidad para reconocer, comprender y regular nuestra emociones y las de los demás”. Desde esta perspectiva, es una habilidad que implica tres procesos: a) percepción, b) comprensión y c) regulación. En cuanto a la percepción, es la forma de reconocer de forma consciente nuestras emociones e identificar qué sentimos y ser capaces de darle una etiqueta verbal. Por otro lado, la comprensión es la capacidad de integrar lo que sentimos dentro de nuestro pensamiento y saber considerar la complejidad de los cambios emocionales. Por último, la regulación es la capacidad de dirigir y manejar las emociones tanto positivas como negativas de forma eficaz.

La autoconciencia emocional es la conciencia de los propios estados internos, recursos e intuiciones. Es reconocer las propias emociones y los efectos que éstas tienen sobre nuestro estado físico, comportamiento y pensamiento. La autoconciencia es el eje básico de la inteligencia emocional, por cuanto la toma de conciencia de nuestros estados emocionales es el punto de partida para otras habilidades de la inteligencia emocional como el autocontrol, la empatía y las habilidades sociales.

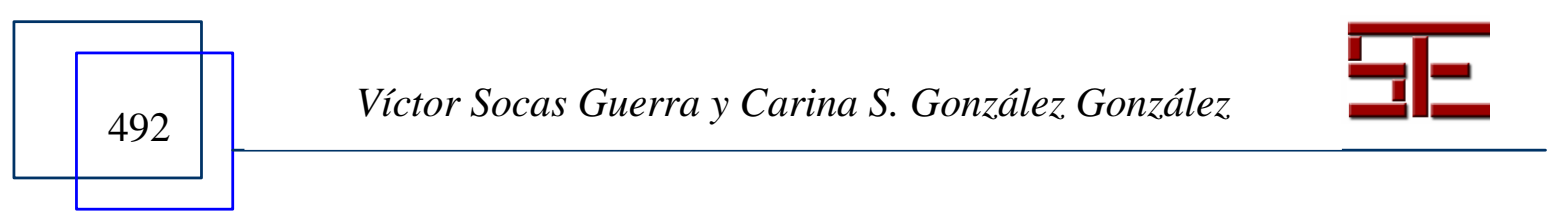




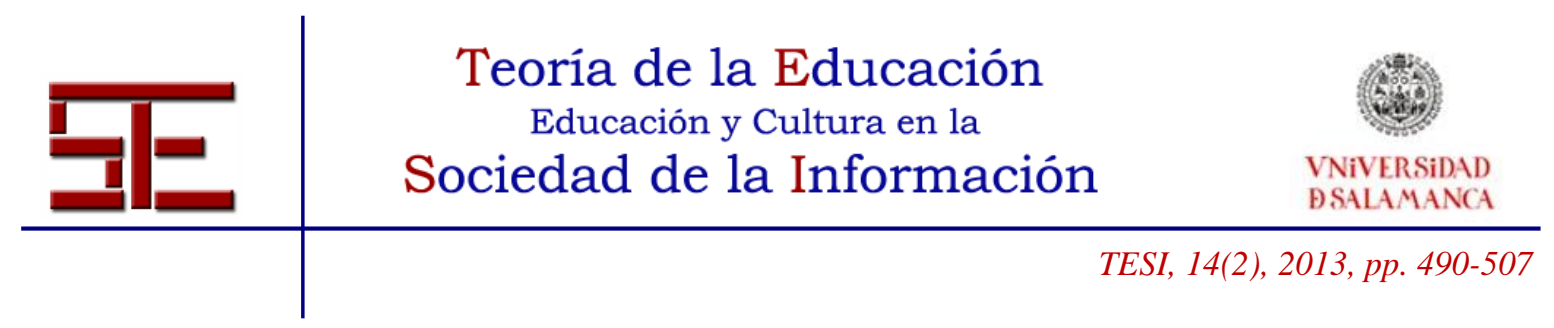

En cuanto a las habilidades sociales podemos decir que la inteligencia emocional refleja la manera en que las personas interactúan con los demás (Goleman, 1996). La inteligencia emocional tiene un componente intrapersonal y un componente interpersonal. Lo intrapersonal comprende las capacidades para la identificación, comprensión y control de las emociones en uno mismo, que se manifiestan en la autoconciencia y el autocontrol. El componente interpersonal, comprende a su vez la capacidad de identificar y comprender las emociones de las otras personas (empatía) y poseer habilidades sociales (Vivas, Gallego y González, 2007).

En particular, en este trabajo trabajaremos sobre las habilidades sociales, trabajando sobre elementos tales como comunicación, influencia, liderazgo, catalización del cambio, resolución de conflictos, colaboración y cooperación y habilidades para el trabajo en equipo, aplicando principios de aprendizaje colaborativo apoyado por ordenadores (CSCL) (Soller y Lesgold, 2000).

Asimismo, cabe destacar el lenguaje del arte como recurso efectivo para la expresión y educación emocional. Este lenguaje se apoya en el principio de la comunicabilidad de la experiencia mediado por la subjetividad. En consecuencia, el arte se constituye en una estrategia de la educación emocional para la mejora de los procesos expresivocomunicativos e intersubjetivos de los sujetos (Vivas, Gallego y González, 2007) y como medio para la conexión y expresión de las emociones, destacando el uso del cine como estrategia para educar actitudes y sentimientos (De La Torre, 2000).

Dada la penetración de los teléfonos móviles en la sociedad de la información y en particular, el uso que hacen de los mismos los estudiantes tanto en las escuelas secundarias como universidades, los dispositivos móviles pueden llegar a ser un instrumento importante de apoyo al aprendizaje (Castells et al., 2007; Sánchez et al., 2009). Podemos afirmar entonces que el aprendizaje móvil o Mobile Learning (mLearning), es una fuerte tendencia en educación (Holzinger et al., 2005; Conde et al., 2008;). Diversos autores han estudiado las potencialidades pedagógicas del m-Learning, afirmando que los dispositivos móviles promueven prácticas interactivas, facilitando la comunicación entre pares, el intercambio de datos, la interacción cara a cara y la colaboración (Roschelle, 2003; Attewell, 2005; Chan et al., 2006; Chirino et al., 2010). Por ello, en este trabajo haremos uso de los dispositivos móviles para propiciar la colaboración y las prácticas de creación interactivas.

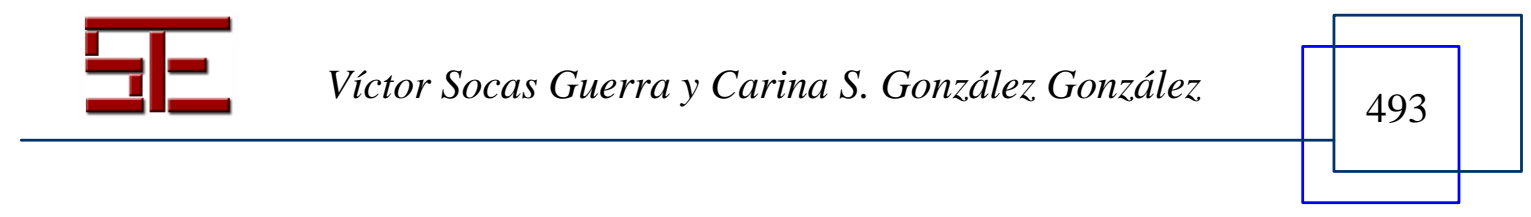




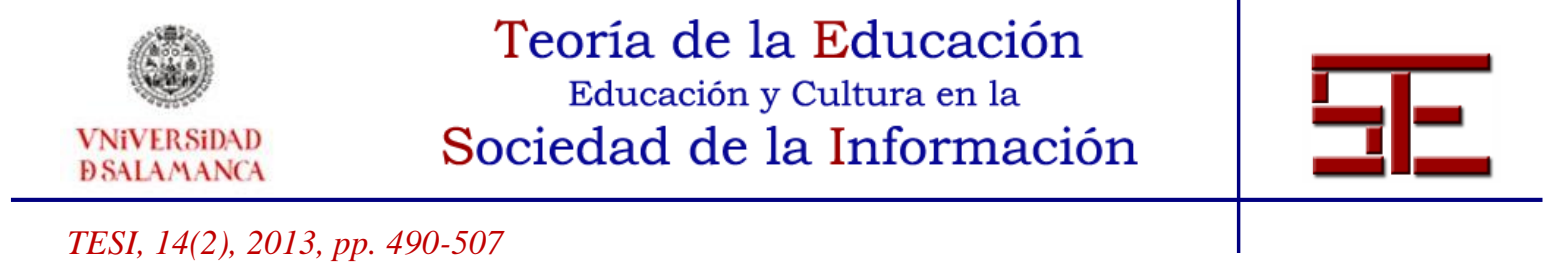

Por otra parte, la creación de relatos digitales permite facilitar la alfabetización digital, aumentar el vocabulario y mejorar el lenguaje, al mismo tiempo que se despierta la motivación hacia el aprendizaje y se facilita la puesta en práctica de los conocimientos que han aprendido en el centro educativo. Existen un gran número de aplicaciones con los que se pueden realizar producciones audiovisuales en microformatos. Nuestros estudiantes disponen de smarthphones con cámaras fotográficas, vídeo, grabadora de voz, y reproductores MP3 y MP4. Con esto, podemos crear historias narrativas digitales. Asimismo, podemos ver otras experiencias exitosas que combinan narrativa digital y $\mathrm{m}$ learning (Arnedillo Sánchez \& Tangney, 2006). Por tanto, uno de nuestros objetivos ha sido el aprovechar las posibilidades que nos ofrece la narrativa digital o digital storytelling (Ohler, 2008) utilizando los dispositivos móviles para la educación emocional al mismo tiempo que se ponían en práctica los conocimientos de la asignatura de Lenguajes y Medios Audiovisuales (Socas y González, 2012).

A continuación se describirá una experiencia educativa desarrollada dentro de una asignatura artística basada en la creación de narrativas digitales con dispositivos móviles y utilizados como estrategias de expresión artística y educación emocional.

\section{2.- EXPERIENCIA}

\subsection{Muestra}

La muestra estuvo compuesta por 24 estudiantes cuyas edades estaban comprendidas entre 18 y 23 años, del 3er Curso de la Escuela de Arte Pancho Lasso, dentro del Ciclo de Lenguajes y Medios Audiovisuales. En cuanto al género, la distribución fue de un $45 \%$ de mujeres y un $55 \%$ de varones.

\subsection{Materiales}

Los materiales utilizados en la experiencia fueron los siguientes:

- Móviles con cámara (tipo smarthphones)

- Ordenadores

- Software de edición de vídeo: Adobe Premiere

- Software de montaje de para el prototipo interactivo: Powerpoint, Flash 


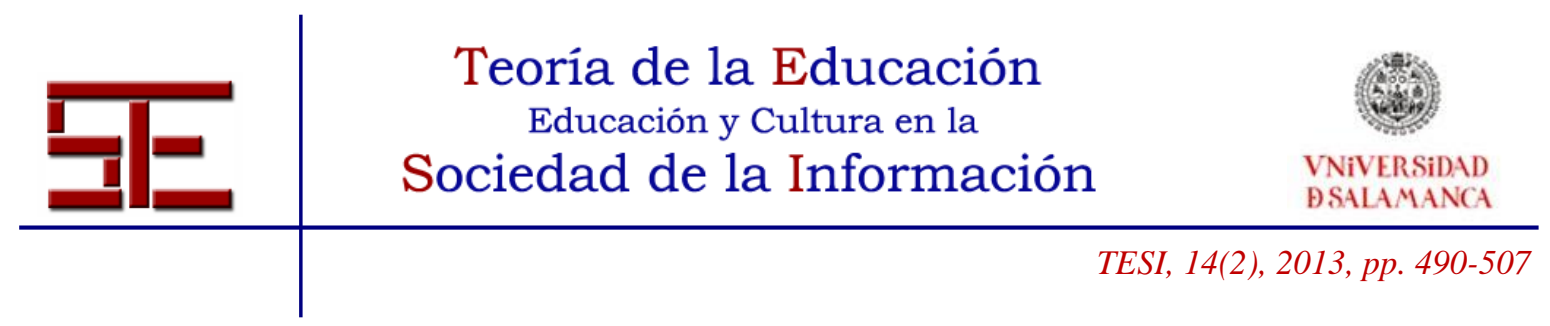

\subsection{Metodología}

El trabajo grupal fue estructurado de tal forma que se siguieran los cinco principios de aprendizaje colaborativo: a) interdependencia positiva, b) interacción cara a cara, c) responsabilidad individual y de grupo, d) aprendizaje de habilidades sociales y e) revisión del proceso del grupo [4]. De esta forma, para realizar el proyecto grupal los 24 estudiantes del curso se organizaron en 6 grupos de 3 a 4 personas asumiendo diferentes roles en el grupo (realizador, actores, editor).

Las actividades de enseñanza-aprendizaje se distribuyeron durante el curso 2011-2012 (15 semanas) de la siguiente manera:

\begin{tabular}{|c|c|}
\hline Actividades & Semanas \\
\hline $\begin{array}{l}\text { 1. Clases magistrales y demostración del } \\
\text { profesor a los estudiantes de los } \\
\text { procedimientos y técnicas específicas a } \\
\text { utilizar. } \\
\text { 2. Realización de un pre-test r sobre } \\
\text { competencias TIC y competencias } \\
\text { emocionales. } \\
\text { 3. Clases magistrales y demostración del } \\
\text { profesor conceptos básicos relacionados con } \\
\text { la inteligencia emocional (conductas } \\
\text { agresivas, inhibidas, asertivas). }\end{array}$ & 3 semanas \\
\hline $\begin{array}{l}\text { 4. Ejercicios de reconocimiento emocional de } \\
\text { respuestas agresivas, inhibidas y asertivas a } \\
\text { determinadas situaciones }\end{array}$ & 1 semana \\
\hline $\begin{array}{l}\text { 5. Desarrollo del ejercicio } \\
\text { audiovisual con móviles } \\
\text { interactivo. }\end{array}$ & 6 semanas \\
\hline $\begin{array}{l}\text { 7. Presentación por parte de los grupos de los } \\
\text { proyectos realizados. }\end{array}$ & 1 semana \\
\hline
\end{tabular}

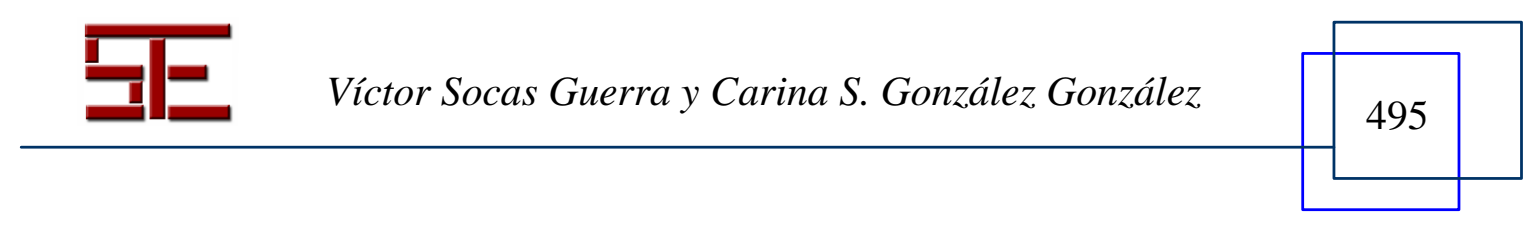




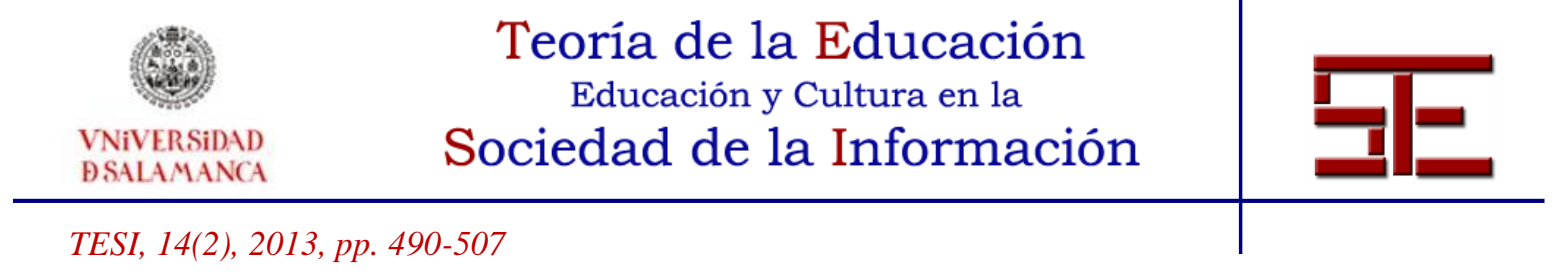

\begin{tabular}{|l|l|}
\hline Actividades & Semanas \\
\hline $\begin{array}{l}\text { 8. Propuestas para la reflexión y y } \\
\text { profundización sobre las conductas } \\
\text { observadas en los proyectos. }\end{array}$ & \\
9. Realización de un cortometraje libre & 4 semanas \\
10. Realización de un post-test de competencias & \\
TIC y competencias emocionales. &
\end{tabular}

Tabla 1. Actividades de enseñanza-aprendizaje realizadas durante el curso

Respecto al ejercicio audiovisual realizado por los alumnos, el mismo se estructuró en dos partes principales:

a) $1^{\circ}$ Parte: A partir de los conocimientos adquiridos en la asignatura lenguaje y medios audiovisuales, los alumnos deben realizar la grabación de tres problemas de su vida cotidiana y plantear tres soluciones para cada problema, teniendo en cuenta que estas soluciones tienen que dar diferentes respuestas emocionales tipo: agresiva, inhibida y asertiva. Con este material audiovisual cada grupo construye un prototipo interactivo (PowerPoint y Flash), donde el usuario, puede a partir de ver el audiovisual del problema, para luego identificar la solución del mismo clasificándola en una respuesta del tipo agresiva, inhibida y asertiva.

b) $2^{o}$ Parte: Los alumnos realizan individualmente un cortometraje libre de duración máxima de 6 minutos, especificando los cambios de estados emocionales que se platean en la narrativa realizada.

Los objetivos que se persiguieron con esta actividad fueron los siguientes:

a) Conocer el lenguaje de las imágenes en movimiento, los códigos y convenciones lingüísticas que de ellos se derivan.

b) Adquirir los conocimientos pertinentes de los mecanismos expresivos y funcionales característicos, para, mediante la asimilación y reflexión, ser capaz de funcionar y utilizar de manera autónoma el lenguaje de las imágenes en una

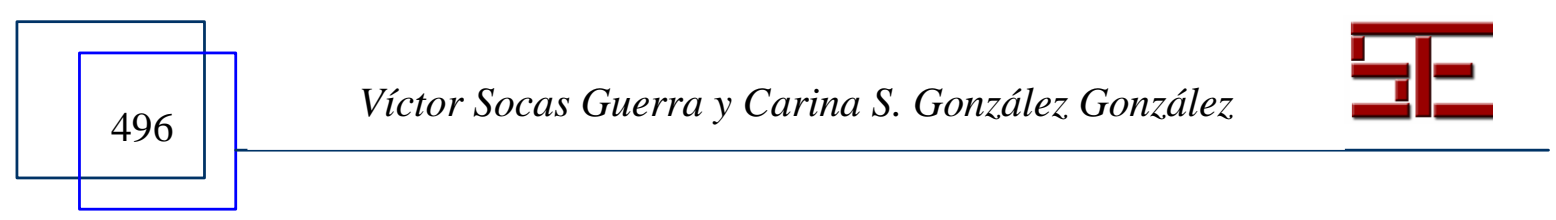




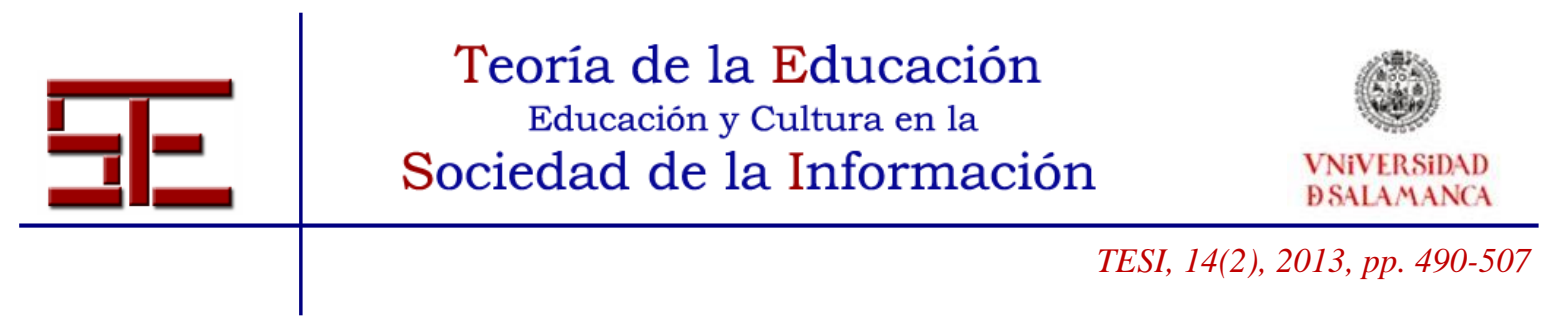

búsqueda e investigación con el fin de encontrar soluciones equilibradas en el proceso de creación audiovisual.

c) Adquirir un dominio de las estructuras emocionales en la narrativa audiovisual.

Para ello, específicamente se trabajaron y aseguraron los siguientes conceptos de la narrativa audiovisual:

a) El espacio unitario.

b) Encuadre y selección de la realidad.

c) Elección y ocultación.

d) La profundidad de campo como factor expresivo.

e) De la toma al plano. La escala de planos.

f) Altura y angulación de la cámara.

g) El movimiento del punto de vista. El zoom como falso movimiento. Lo audiovisual tiene estructura temporal. La elipsis. Linealidad. Saltos temporales.

h) La secuencia.

i) La transición entre planos.

j) La continuidad visual y racord.

k) El salto del eje de acción.

1) La articulación del espacio y del tiempo.

m) El montaje como elemento integrador.

n) Aplicación con criterio de los diferentes estados emocionales dentro de la narrativa.

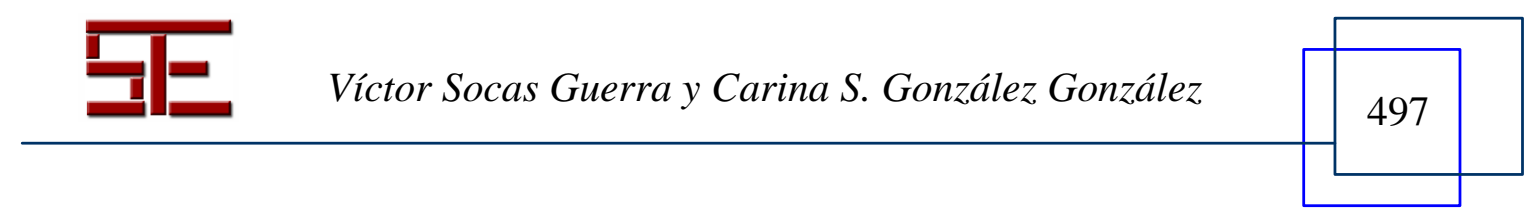




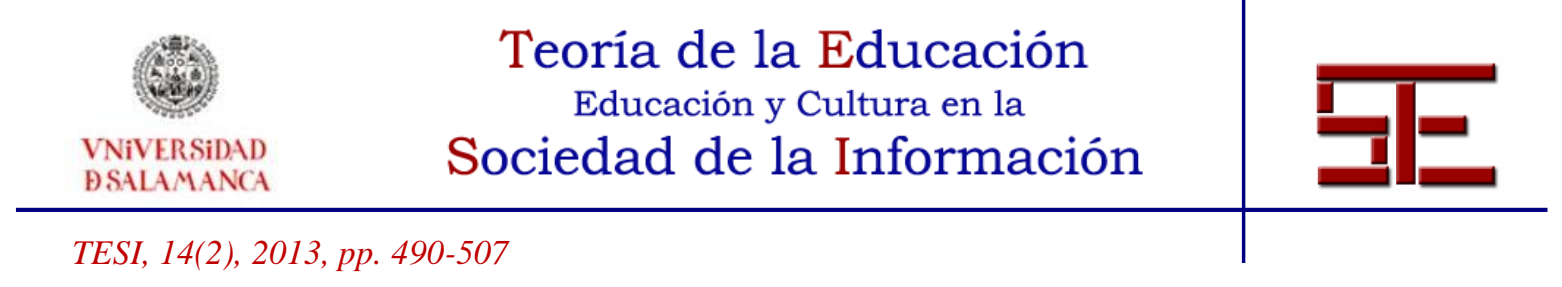

Para la evaluación de la actividad a nivel académico se tuvieron en cuenta los siguientes criterios:

a) Destreza perceptiva (emocional).

b) Conocimiento práctico de los procesos derivados de los distintos contenidos temáticos.

c) Utilización y uso correcto de los diferentes aparatos (vídeo, video-cámaras, proyectores, mezcladores, vídeo-sonido, etc.).

d) Conocimiento y uso correcto de la terminología profesional.

e) Sensibilidad para expresarse en el medio de una forma personal e independiente así como crear nuevos modelos estéticos.

f) Capacidad crítica para opinar sobre los distintos valores, ya sean estéticos o técnicos del lenguaje de las imágenes.

g) Capacidad e imaginación creativa.

h) La asimilación y comprensión de los mecanismos y códigos del lenguaje de las imágenes.

i) Crítica y análisis de secuencias de programas audiovisuales y lecturas recomendadas.

\subsection{Desarrollo}

El ejercicio de creación audiovisual se desarrolló poniendo en práctica los conocimientos adquiridos en la asignatura lenguaje y medios audiovisuales en donde los estudiantes realizaron la grabación de tres problemas de su vida cotidiana y plantearon tres soluciones para cada problema, teniendo en cuenta que estas soluciones con diferentes respuestas emocionales: a) agresiva; b) inhibida y c) asertiva. Con los materiales audiovisuales elaborados, cada grupo construyó un prototipo de narrativa interactiva, donde el usuario

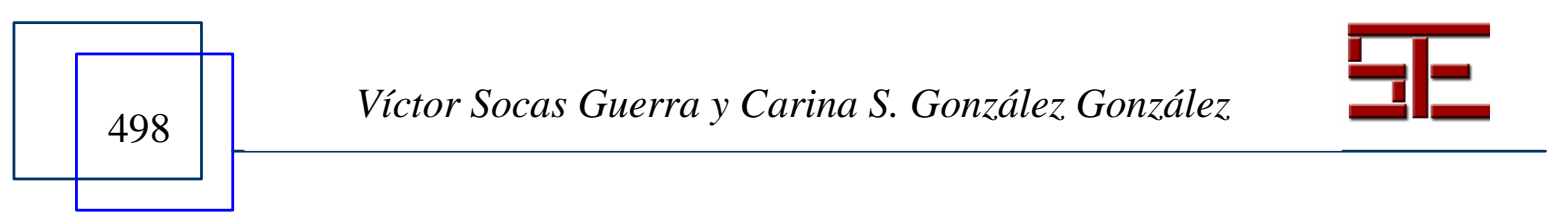




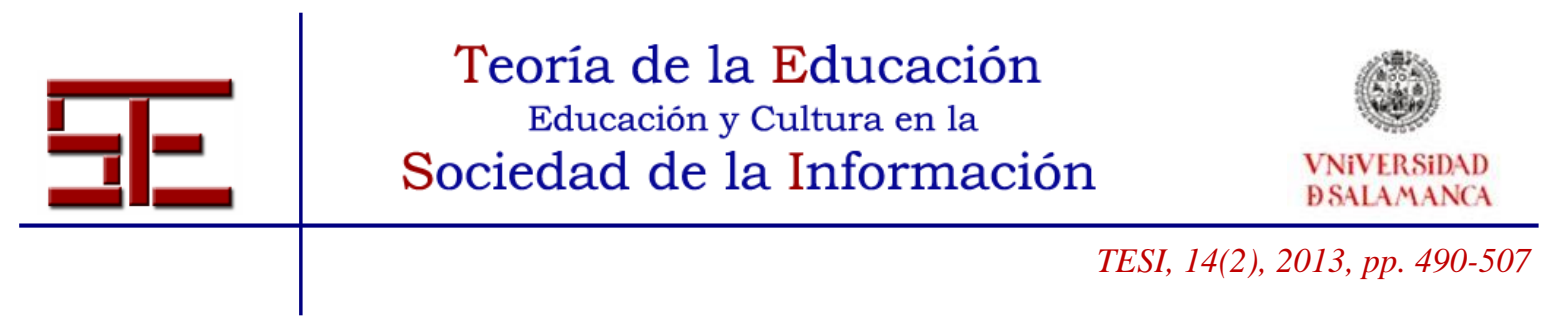

a partir de ver el audiovisual del problema puede elegir la solución del mismo (agresiva, inhibida y asertiva).

En la Figura 1 podemos ver un ejemplo de 4 vídeos que contienen la presentación de una situación problema y las tres soluciones propuestas. En este ejemplo, el problema presentado es la situación en la que una chica de 17 años vuelve a su casa a las 6 de la mañana después de haber pasado fuera toda la noche, sin permiso de su madre, y su madre le abre la puerta. Ante esta situación, la madre tiene diferentes estilos de afrontamiento. En el prototipo interactivo, el objetivo será identificar cuál de las tres soluciones propuestas al problema inicial es la refleja una actitud positiva, negativa o neutra respecto al personaje de la madre.

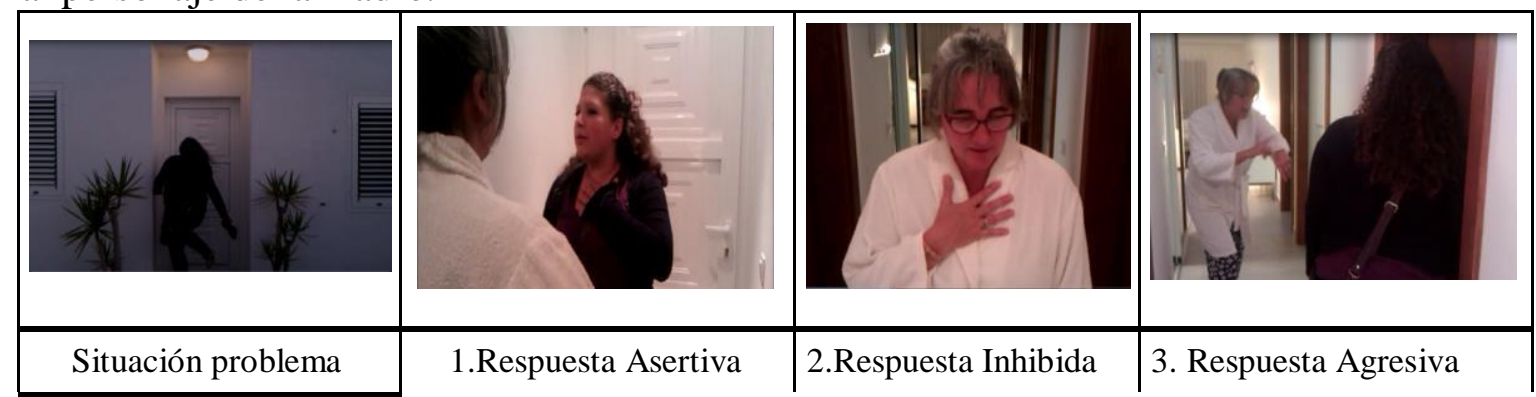

Figura 1. Ejemplo de los 4 tipos de vídeos creados por los grupos, presentando la situación problema y 3 tipos respuestas emocionales diferentes.

En total, se han realizado 18 proyectos audiovisuales, cada uno de estos planteando un problema cotidiano y un total de 54 audiovisuales con las 54 soluciones de respuestas emocionales (18 agresivas, 18 inhibidas y 18 asertivas) y 18 prototipos interactivos.

Para estudiar la dinámica de trabajo grupal, se llevaron a cabo una serie de observaciones estructuradas en las sesiones presenciales siguiendo las 12 categorías de Bales (1999). Esta observación nos ha permitido identificar las interacciones dentro del grupo, así como la comunicación emitida por cada sujeto hacia cada uno de los otros miembros o hacia todo el grupo. Por otra parte, se realizó una entrevista con el líder del grupo para recabar más información sobre el grupo.

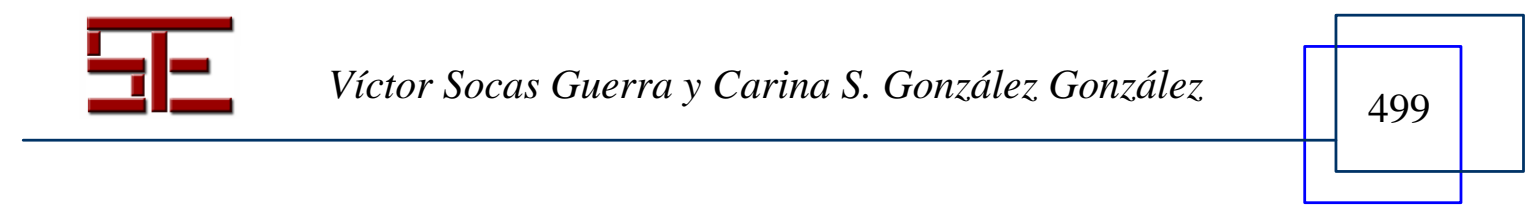




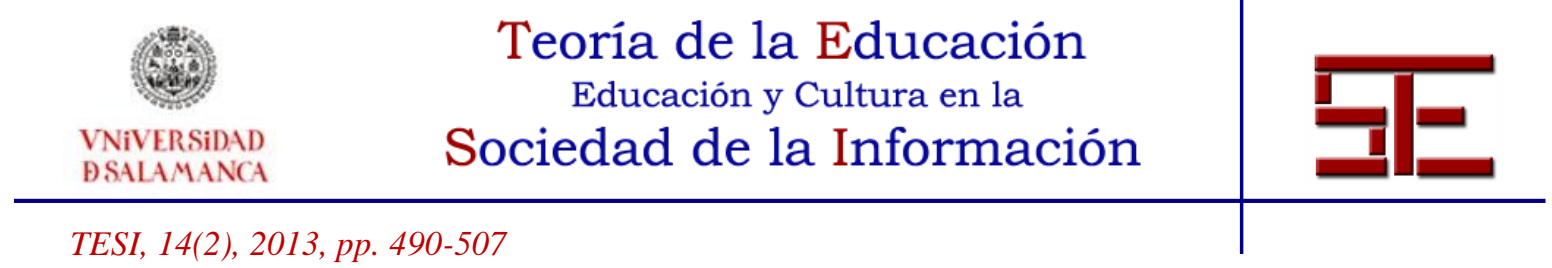

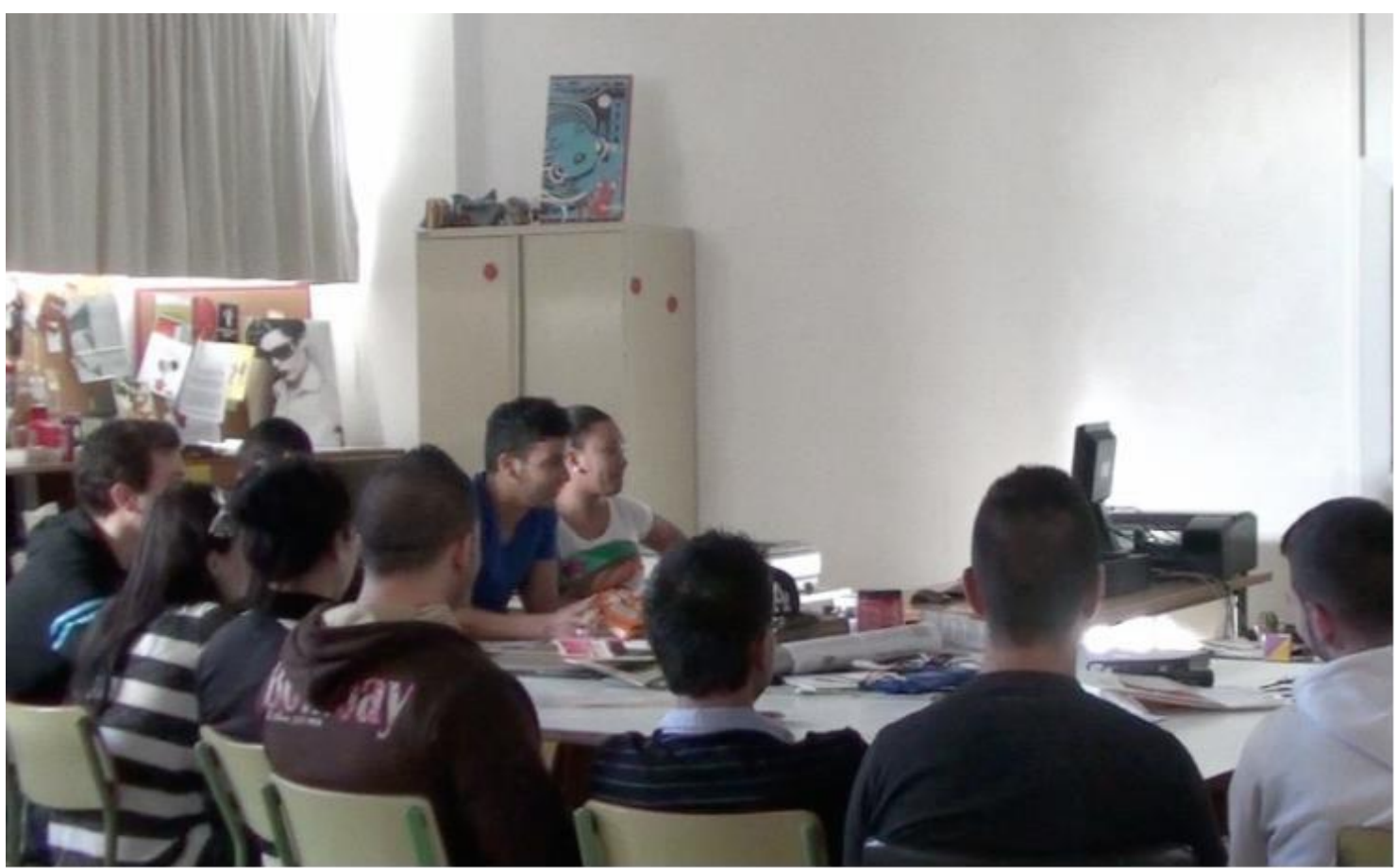

Figura 2. Sesión de trabajo grupal de crítica y análisis de secuencias audiovisuales.

\section{3.- RESULTADOS}

En esta sección se presentarán los resultados obtenidos en los tests realizados, pre y post, así como las evaluaciones realizadas durante el desarrollo de la experiencia por dimensión analizada.

\subsection{Dimensión tecnológica}

Los resultados obtenidos sobre la dimensión tecnológica presentan un alumnado altamente conectado: el $80 \%$ de los alumnos tenía ordenador personal, el $79 \%$ dispone de conexión a Internet y se conecta habitualmente desde casa. Asimismo, el 87\% utiliza programas de edición de imágenes, audio y vídeo de forma cotidiana, por lo que nuestro alumnado ya tiene conocimientos básicos tecnológicos para la creación audiovisual, no así, las competencias específicas curriculares de la asignatura.

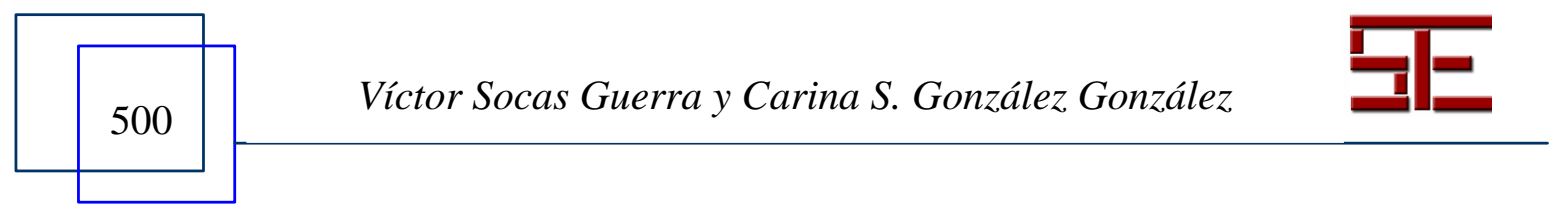




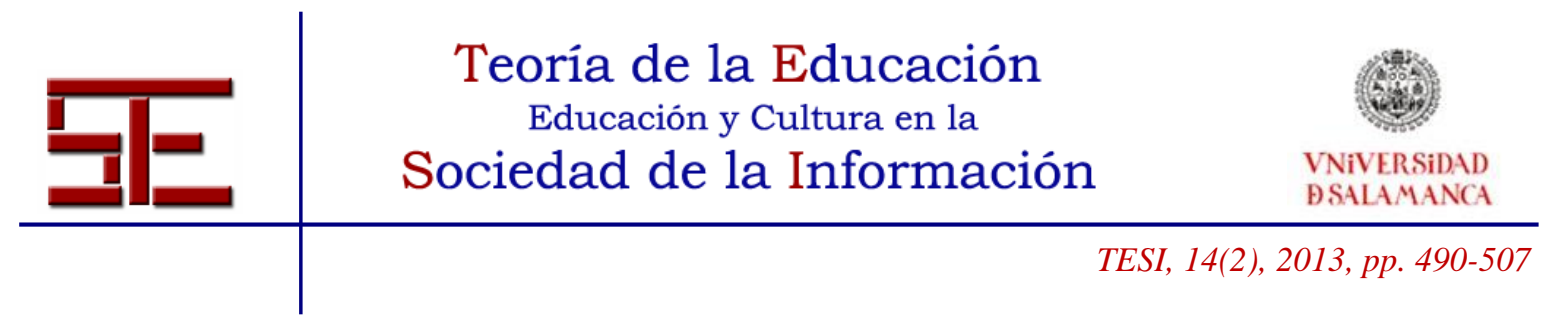

Además, el $100 \%$ dispone de un teléfono móvil, aunque solo el $77 \%$ posee capacidades de acceso a Internet desde el dispositivo. Sobre el uso que hacen del móvil podemos destacar los siguientes (Tabla 2).

\begin{tabular}{|l|l|}
\hline Uso & $\%$ \\
\hline Hablar & $93 \%$ \\
Enviar SMS & $67 \%$ \\
Chavegar & $67 \%$ \\
Sacar fotos & $47 \%$ \\
Redes sociales & $60 \%$ \\
Grabar vídeos & $67 \%$ \\
Otros usos & $13 \%$ \\
\hline
\end{tabular}

Tabla2. Tipos de usos del móvil

\subsection{Dimensión audiovisual}

Respecto al uso del móvil como instrumento de creación audiovisual, el 69\% piensa que es una herramienta útil y el $62 \%$ que puede ser utilizada para contar historias. En este sentido, algunas de las ventajas que encontraron los alumnos utilizando el móvil en el ejercicio de estados emocionales fueron las siguientes:

- Hace que la grabación sea más amateur por lo tanto más relista y menos artificial.

- Es un instrumento que siempre lo tienes a mano.

- Es un recurso fácil de utilizar y su calidad puede ser usada según para que objetivos.

- Es útil para ubicar un personaje que contrarreste mucho con otro.

- Es cómodo, fácil y bastante casero.

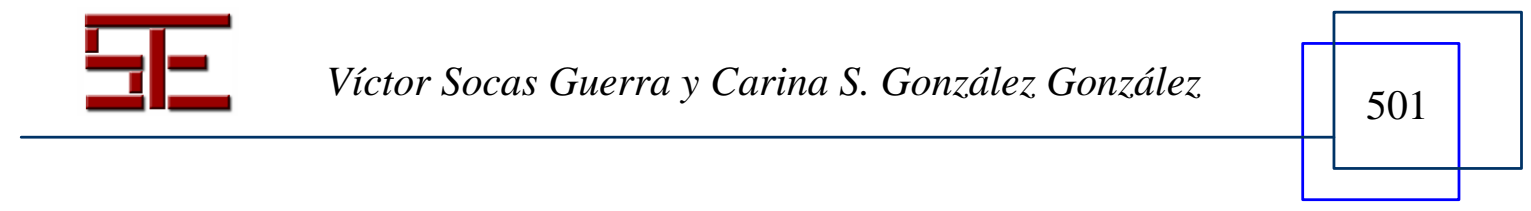




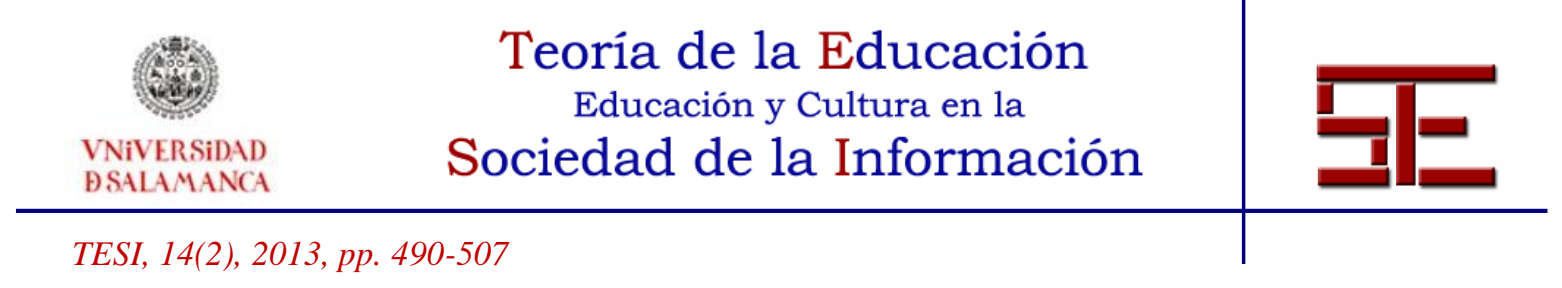

- Es un medio a la mano ligero y fácilmente transportable.

En cuanto a las desventajas halladas del uso del móvil como herramienta de creación audiovisual, podemos citar las siguientes:

1. La calidad final del móvil es muy inferior a la de una cámara, por lo tanto para trabajos más "serios" no convendría su uso.

2. Limitaciones en las prestaciones de la cámara.

3. Poca calidad de imagen y sonido.

4. Poca memoria.

5. Poca estabilidad al no poder usar trípode.

6. No poder utilizar el enfoque.

7. Pésima calidad nocturna y con mucha luz.

\subsection{Dimensión colaborativa}

La colaboración en el grupo fue observada durante las sesiones de trabajo grupal de forma presencial, en donde por cada miembro y rol desempeñado en el grupo (realizador, actores, editor), se analizó su comportamiento en referencia a las siguientes categorías de Bales (1999):

1. Solidaridad: da pruebas de solidaridad, alienta, ayuda, valoriza a los demás.

2. Distensión: Trata de disminuir la tensión, bromea, ríe, se declara satisfecho.

3. Acuerdo: Da su conformidad, acepta tácitamente, comprende.

4. Da sugerencias e indicaciones, respetando la libertad de los demás

5. Da su opinión, analiza, expresa sus sentimientos y sus deseos.

6. Orienta, informa, repite, aclara, confirma.

7. Solicita orientación, información, repetición, confirmación

8. Solicita una opinión, una evaluación, un análisis, la expresión de un sentimiento.

9. Solicita sugerencias, instrucción, medios posibles de acción.

10. Desacuerdo: desaprueba, rechaza pasivamente, niega su ayuda.

11. Tensión: manifiesta una tensión, pide ayuda, se retira de la discusión.

12. Antagonismo: da pruebas de oposición, denigra a los demás, se afirma a sí mismo.

Esta observación nos ha permitido identificar, analizar y trabajar en los ejercicios emocionales las habilidades sociales de los estudiantes y potenciar la comunicación asertiva en cuanto a que sean capaces de lograr competencias comunicativas asertivas,

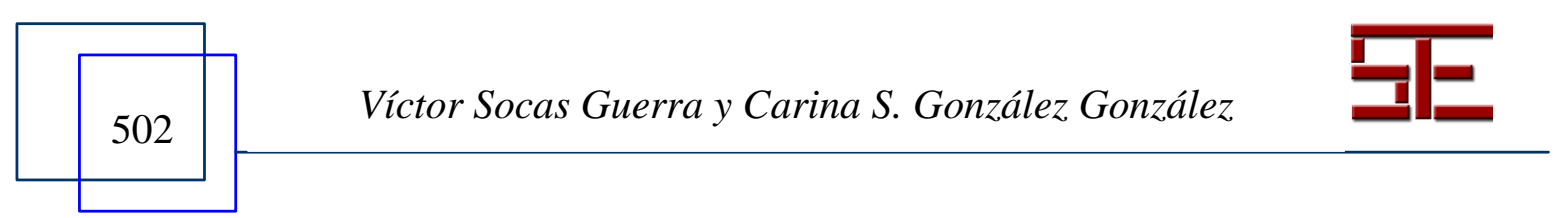




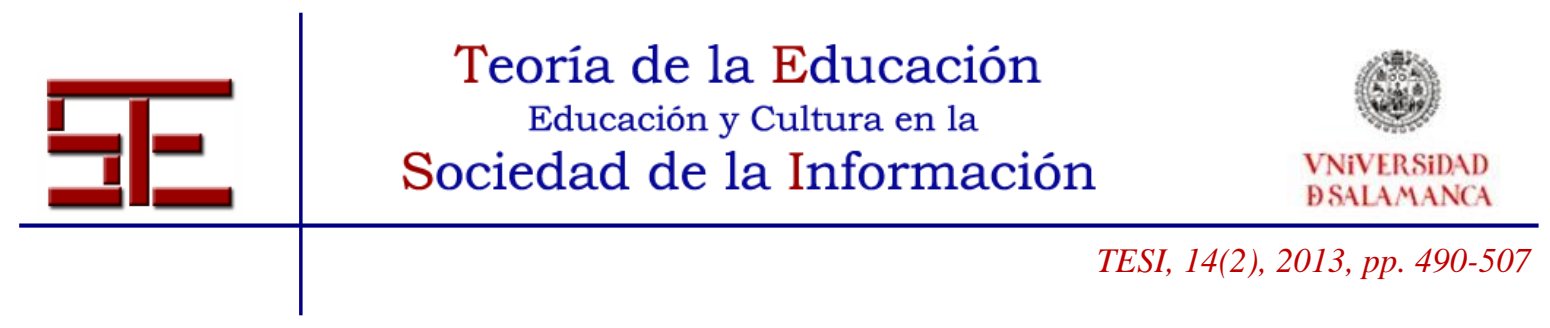

tales como: a) expresar sentimientos y deseos positivos y negativos de una forma eficaz, sin negar o menospreciar los derechos de los demás y sin crear o sentir vergüenza, b) discriminar las ocasiones en que la expresión personal es importante y adecuada y c) defenderse, sin agresión o pasividad, frente a la conducta poco cooperadora, apropiada o razonable de los demás.

\subsection{Dimensión emocional}

Respecto a la dimensión sobre el conocimiento emocional, se evaluaron las habilidades sobre percepción emocional, comprensión de sentimientos y regulación emocional. El test para evaluar los estados emocionales se basó en el test TMMS-24 elaborado por Fernández-Berrocal, Extremera y Ramos (2005).

Siguiendo el TMMS-24, se preguntó a los alumnos en qué medida eran capaces de sentir, expresar, comprender y regular los sentimientos de forma adecuada antes y después de realizar el ejercicio, obteniéndose los siguientes resultados sobre las competencias emocionales de los estudiantes:

- Antes de realizar ejercicio el $51 \%$ era capaz de sentir y expresar sus sentimientos de forma adecuada (bastante-mucho) y el $13 \%$ no sabía expresarse correctamente, mientras que después de hacer el ejercicio el $100 \%$ manifestó que era capaz de expresar sus sentimientos de forma adecuada (de los cuales el 19\% muy bien).

- Antes del ejercicio el 6\% no era capaz de comprender sus estados emocionales mientras que 44\% lo hacía bastante bien. Después de realizar el ejercicio, el 100\% manifestó que era capaz de comprender sus estados emocionales (de los cuales el $56 \%$ lo hace muy bien).

- Antes de realizar el ejercicio el $12 \%$ no sabía cómo regular sus emociones (nadapoco), y después de la realización del ejercicio este porcentaje disminuye a la $\operatorname{mitad}(6 \%$-poco).

- El $69 \%$ de los estudiantes considera que el medio es idóneo para una fácil interpretación emocional y que las propuestas sobre estados emocionales (inhibidas, asertivas, agresivas) planteadas han sido fáciles (81\%).

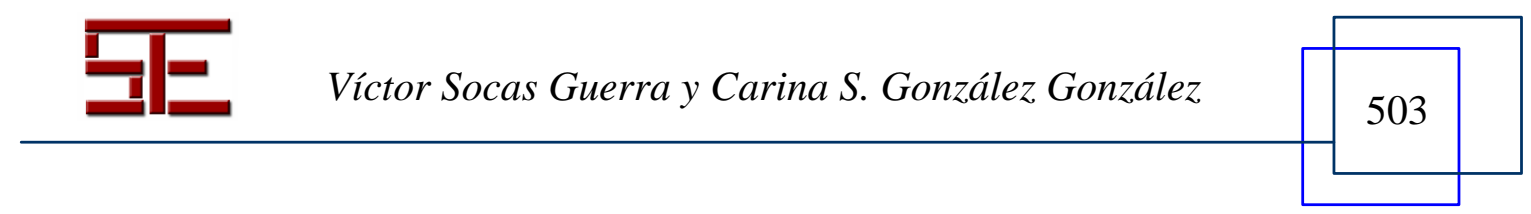




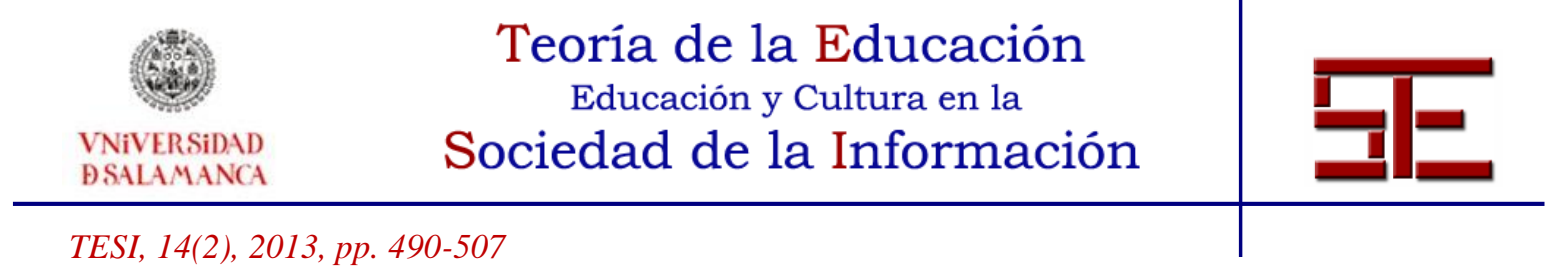

\section{4.- CONCLUSIONES}

En este trabajo se ha presentado una experiencia de innovación educativa desarrollada con estudiantes de la Escuela de Arte Pancho Lasso dentro del ciclo de Lenguajes y Medios Audiovisuales. En esta experiencia se han aplicado diferentes técnicas:

a) aprendizaje colaborativo soportado por ordenador para la enseñanza de habilidades sociales,

b) narrativa digital para la enseñanza de habilidades emocionales y

c) utilización de dispositivos móviles para la enseñanza de competencias específicas de la asignatura en la creación de microformatos audiovisuales y competencias tecnológicas.

Los estudiantes se han mostrado altamente motivados y han mostrado una evolución positiva tanto en el aprendizaje de las competencias específicas de la asignatura, como en las competencias sociales, emocionales y tecnológicas.

Del análisis de los datos recogidos durante el desarrollo de la experiencia, podemos destacar que la evolución de los estudiantes ante este tipo de ejercicios ha sido altamente positiva, no solo de cara a su aprendizaje de contenidos específicos de la asignatura, sino en el reconocimiento de comportamientos, actitudes y respuestas emocionales ante distintas situaciones de la vida cotidiana y en la propia clase.

Respecto al ejercicio de creación audiovisual, hemos observado que en la primera parte de la actividad dirigida y pautada por el profesor hacia el trabajo sobre las respuestas emocionales (asertiva, inhibida y agresiva) a una situación problema, los alumnos fueron adquiriendo una actitud crítica y constructiva sobre los diferentes estados emocionales, desarrollando una capacidad de análisis en sus trabajos y en el de sus compañeros, entendiendo y familiarizándose con los estados emocionales como herramienta fundamental en la construcción narrativa. Por otra parte, en la segunda parte de la actividad, siendo un audiovisual de creación libre, los estudiantes demostraron una mayor destreza en la construcción narrativa, enriqueciendo los audiovisuales realizados y aumentando la variedad de las propuestas y la complejidad emocional de las mismas.

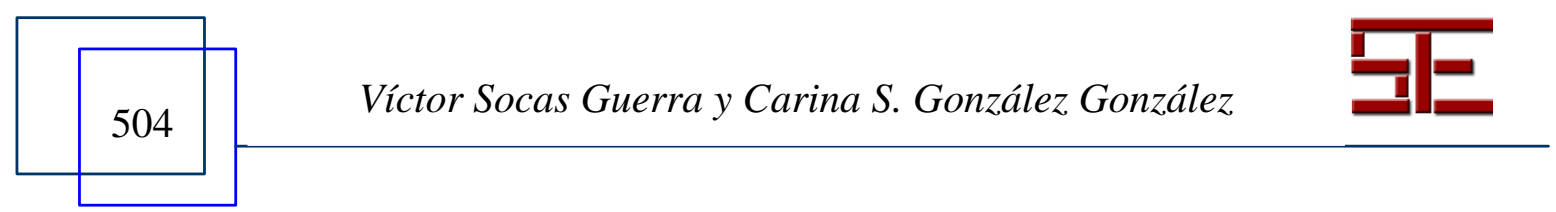




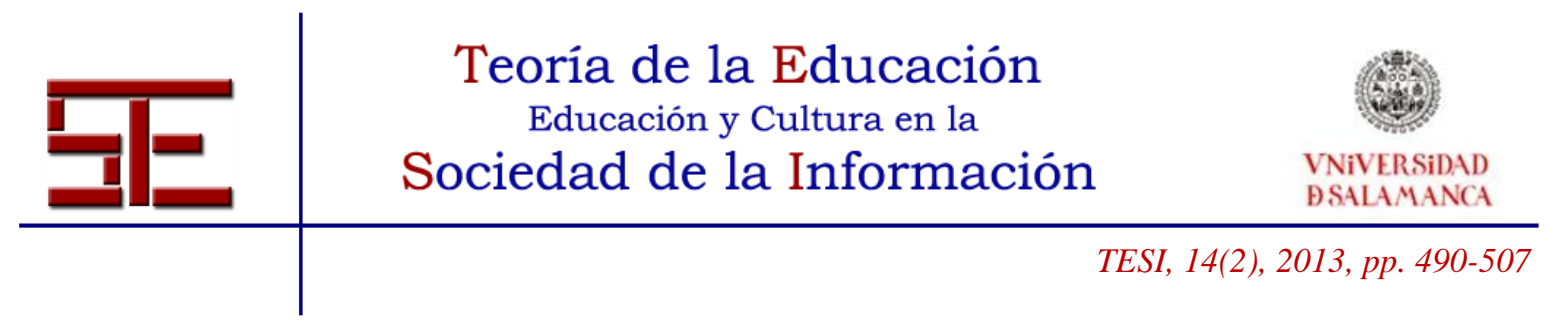

Creemos por tanto que la educación emocional es un elemento pendiente de incluir en las competencias transversales. Por último, destacar el potencial educativo de la narrativa digital y los dispositivos móviles, que son elementos que se encuentran al alcance del profesorado y del alumnado y que pueden convertirse en poderosos aliados tanto dentro como fuera del aula. Por otra parte, los dispositivos móviles propician la comunicación, intercambio de datos y colaboración entre los estudiantes (Zurita y Nussbaum, 2004).

Actualmente estamos estudiando la relación de las narrativas creadas por los estudiantes, según: los hechos o incidentes mostrados, los elementos de transición (relación), la organización cronológica del mensaje, los tiempos (percepción, psicológico), los planos, entre otros elementos estructurales narrativos. Además, se han realizado pruebas de experiencia de usuario (UX) y Eyetracker con los mejores prototipos interactivos creados por los estudiantes y estamos analizando los datos recogidos en las mismas.

\section{5.- BIBLIOGRAFÍA}

Arnedillo Sánchez, I. \& Tangney B. (2006). Mobile Technology: Towards overcoming technology \& time constraints in digital video production. IADIS International Conference on Mobile Learning. 256 - 259.

Bales, R.F. (1999). Social interaction systems: Theory and measurement. Transaction Publishers.

Castells, M., Fernández Ardevol, M., Linchuan Qiu, J. y Sey, A. (2007). Comunicación móvil y sociedad, una perspectiva global. Barcelona: Ariel, Fundación Telefónica.

Chan, T., Roschelle, J., Hsi, S., Kinshuk, Sharples, M., Brown, T., Patton, C., Cherniavsky, J., Pea, R., Norris, C., Soloway, E., Balacheff, N., Scardamalia, M., Dillenbourg, P., Looi, C., Milrad, M., \& Hoppe, U. (2006). One-to-one technologyenhanced learning: An opportunity for global research collaboration. Research and Practice in Technology Enhanced Learning, 1(1), 3-29.

Chirino, V.; Noguez, J.; Neri, L.; Robledo-Rella, V. y Aguilar, G. (2010). Students perception about the use of mobile devices in self-managed learning activities and learning gains related to mobile learning resources. Book on Mobile Science.

Conde, M.A., Muñoz C., García F.J. (2008). El mLearning y la revolución de los procesos de Aprendizaje. V Simposio Pluridisciplinar sobre Diseño y Evaluación de Contenidos Educativos Reutilizables. Salamanca.

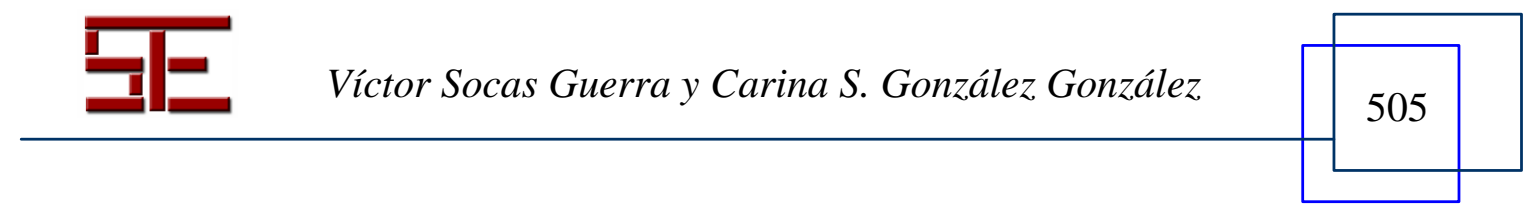




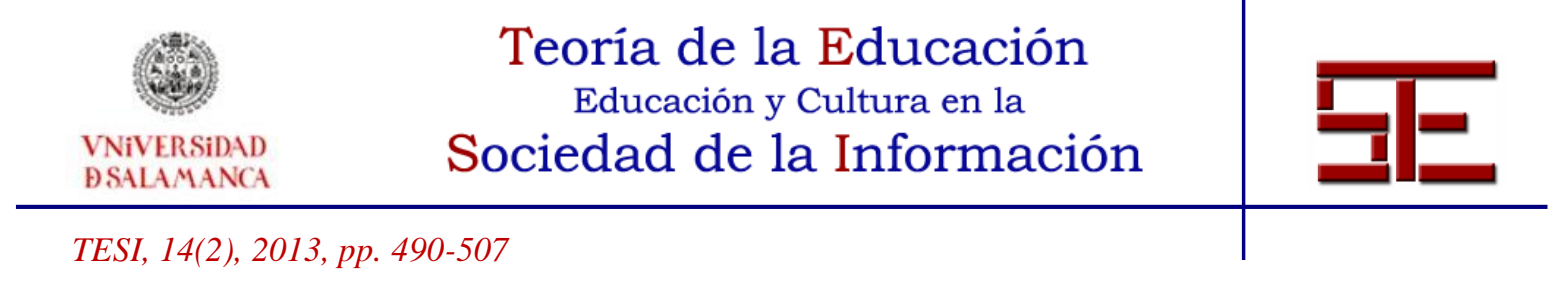

De La Torre, S. (2000). Estrategias creativas para la educación emocional. Revista Española de Pedagogía, LVIII (217), 543-572.

Fernández-Berrocal, P. y Ramos, N. (2002). Corazón y razón. En Fernández-Berrocal, P. y Ramos, N. (Eds.). Corazones inteligentes. (pp. 17-34). Barcelona: Kairós.

Fernández-Berrocal, P., Extremera, N. y Ramos, N. (2005) Validity and reliability of the Spanish modif ed version of the Trait Meta-Mood Scale. Psychological Report, 94, 751-755.

Goleman, D. (1996). La inteligencia emocional. Buenos Aires: Javier Vergara Editor.

Holzinger A., Nischelwitzer A., Meisenberger M. (2005): Lifelong-learning support by m-learning: example scenarios. eLearn Magazine 2005(11): 2.

Ohler, J. (2008). Digital Storytelling in the classroom: new media pathways to literacy, learning, and creativity. Thousand Oaks, California: Corwin Press.

Roschelle J. (2003). Unlocking the learning value of wireless mobile devices. Journal of Computer Assisted Learning (2003) 19(3), 260-272. Blackwell Publishing Ltd

Socas V., González C.S. (2012). Narrativa Digital con Dispositivos Móviles: Una Experiencia para la Educación Emocional. Actas del XIV Simposio Internacional de Informática Educativa (pp 231-234). Andorra. 29 al 31 de Octubre de 2012.

Sánchez, J.; Sáenz, M.; Muñoz, M.; Ramirez, G. y Martín, S. (2009). Situación actual del mLearning. Recuperado el 23 de abril de 2011 en: http://remo.det.uvigo.es

Soller, A. y Lesgold, A. (2000). Modeling the process of collaborative learning. Proceedings of International Workshop on New Technologies in Collaborative Learning, Awaji-Yumetabi, Japan.

Vivas M., Gallego D., González B. (2007). Educar las emociones. Venezuela.

Zurita, G. y Nussbaum, M. (2004). Computer supported collaborative learning using wirelessly interconnected hand-held computers. Computers \& Education. 42 (3), 289-314.

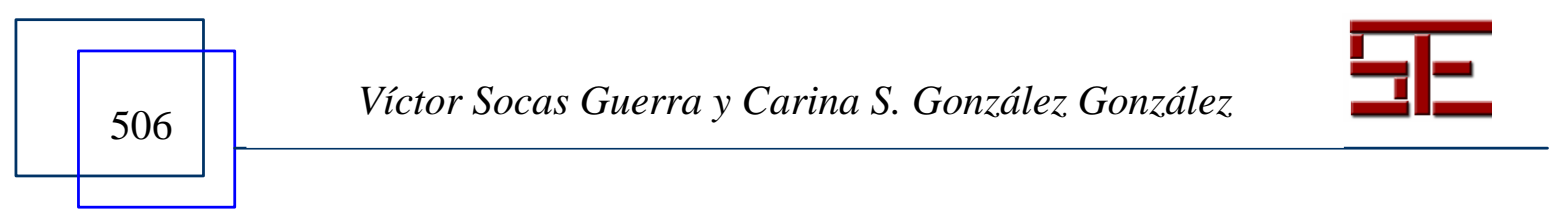




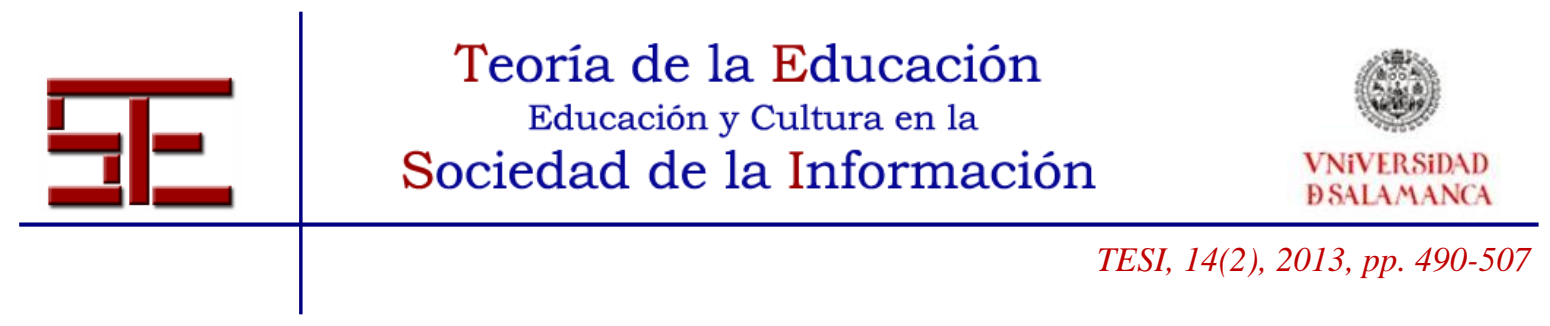

Para citar el presente artículo puede utilizar la siguiente referencia:

Socas Guerra, V. y González González, C. S. (2013). Usos educativos de la narrativa digital: una experiencia de m-learning para la educación emocional. Revista Teoría de la Educación: Educación y Cultura en la Sociedad de la Información. 14(2), 490-507 [Fecha de consulta: dd/mm/aaaa].

http://campus.usal.es/ revistas_trabajo/index.php/revistatesi/article/view/10242/10673

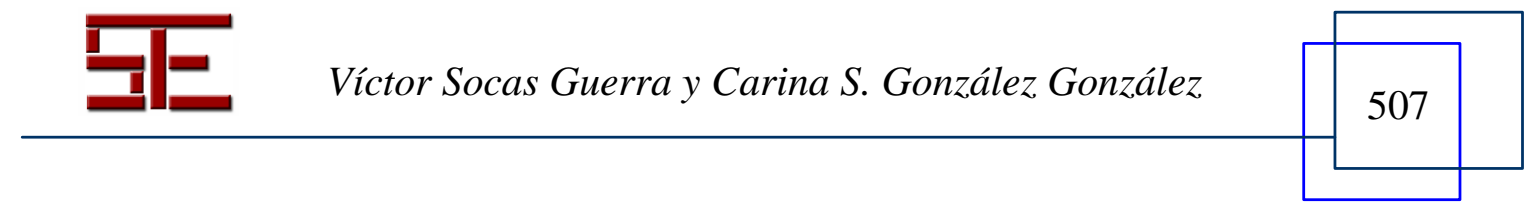

